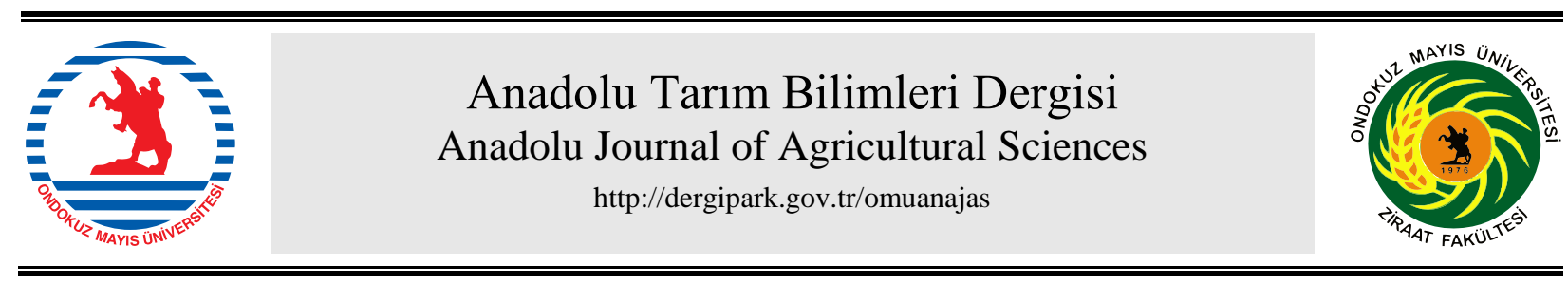

Araştırma/Research

Anadolu Tarım Bilim. Derg./Anadolu J Agr Sci, 33 (2018)

ISSN: 1308-8750 (Print) 1308-8769 (Online)

doi:10.7161/omuanajas.465971

\title{
Gül ekstresinin kolinesteraz inhibisyon potansiyelinin belirlenmesi
}

\author{
Esra Şentürk $^{\mathrm{a}, *}$, Murat Şentürk ${ }^{\mathrm{b}}$ \\ ${ }^{a}$ Ağr İbrahim Çeçen University, School of Health Services, 04100, Agri, Turkey. \\ ${ }^{b}$ Ağrl İbrahim Çeçen University, Pharmacy Faculty, 04100, Agri, Turkey. \\ ${ }^{*}$ Corresponding author/Sorumlu yazar: esracavusoglu87@gmail.com
}

Geliş/Received 01/10/2018 Kabul/Accepted 13/10/2018

\begin{abstract}
ÖZET
Yağ gülü veya Isparta gülü olarak bilinen Rosa damascena Mill., dünya genelinde kokulu güller arasında kültürü yapılan ve ekonomik açıdan önemli olan gül türlerinden bir tanesidir. Isparta gülünden elde edilen uçucu yağ özellikle kozmetik, parfümeri, ilaç ve gıda sanayisinde kullanılmaktadır. Isparta gülü geleneksel olarak gögüs ve karın ağrılarının tedavisinde, kalbin güçlendirilmesi, kabızlık, sindirim sorunları ve sinirsel hastalıkların tedavisinde kullanıldığı bilinmektedir. Alzheimer hastalığının (AD) patogenezi henüz netleşmemesine rağmen, kabul gören teorilerden biri "kolinerjik hipotez" olmuştur. Alzheimer hastalarının beyinlerinde asetilkolin (ACh) ve bütirilkolin (BCh) olarak adlandırılan nöromediyatör düzeylerinde eksiklik görülmüştür. Sırasıyla ACh ve BCh'yi hidroliz eden temel enzimler olan asetilkolinesteraz (AChE) ve bütirilkolinesterazın (BChE) inhibisyonu AD'ye karş1 önemli bir tedavi seçeneği haline gelmiştir. $\mathrm{Bu}$ nedenle, $\mathrm{AD}$ patogenezinde yer alan anahtar enzimler olan AChE ve BChE aktivitelerini önleme faaliyetlerini taramak için bir araştırma başlattık. Bu amaçla, gül suyunun bu enzimler üzerindeki inhibisyon etkilerini inceledik. IC s0 $_{0}$ değerleri AChE için $0.6227 \mu \mathrm{g}$ $\mathrm{ml}^{-1} \mathrm{BChE}$ için $0.1956 \mu \mathrm{g} \mathrm{ml}^{-1}$ olarak belirlendi.
\end{abstract}

\section{Determination of cholinesterase inhibition potential of rose extract}

\section{ABSTRACT}

Rosa Damascena Mill., also known as oil rose or rose of Isparta, is one of the most important roses among the fragrant roses in the world. The essential oil obtained from Isparta rose is used especially in cosmetics, perfumery, pharmaceutical and food industries. Isparta rose is traditionally used in the treatment of chest and abdominal pain, strengthening of the heart, constipation, digestive problems and is used in the treatment of neural diseases. Although pathogenesis of Alzheimer's disease (AD) has not been clarified as yet, one of the most accepted theories has been "cholinergic hypothesis". A deficiency in levels of the neuromediators called acetylcholine (ACh) and butyrylcholine (BCh) has been observed in the brains of $\mathrm{AD}$ patients. Inhibition of acetylcholinesterase (AChE) and butyrylcholinesterase (BChE), the main enzymes which hydrolyze $\mathrm{ACh}$ and $\mathrm{BCh}$, respectively, has happen a major treatment option towards AD. So, we initiated a study to screen their AChE and BChE inhibitory activities, which are the key enzymes taking place in pathogenesis of $\mathrm{AD}$. For this purpose, we investigated the effects of rose water on these enzymes. $\mathrm{IC}_{50}$ values were determined as $0.6227 \mu \mathrm{g} \mathrm{ml}^{-1}$ for $\mathrm{AChE}$ and 0.1956

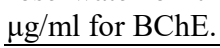

\section{Giriş}

Aromatik ve tıbbi bitkiler arasında çok önemli bir konuma sahip olan güller aynı zamanda yüksek bir ekonomik öneme de sahiptir. Türkiye'de Rosa damascena (Isparta Gülü) 1888 yllından günümüze kadar endüstriyel ölçekli üretilmektedir (Özçelik ve ark., 2011; Özçelik ve ark., 2013). Günümüzde Rosa damascena Mill. bitkilerinden yararlanılarak gül suyu, gül yağı, gül losyonu, gül kremi, gül lokumu, gül reçeli,
Anahtar Sözcükler:

Rosa damascena,

Alzheimer

Asetilkolinesteraz

Butirilkolinesteraz

İnhibisyon
Keywords:

Rosa damascena

Alzheimer

Acetylcholinesterase

Butyrylcholinesterase

Inhibition

(C) OMU ANAJAS 2018 gül şurubu, gül sabunu başta olmak üzere 100'den fazla çeşit ticari ürün elde edilmektedir (Baydar, 2005; Özçelik ve ark., 2011).

Gülden elde edilen ürünlerin (özellikle yağının) psikolojik rahatsızlıklardan kaynaklanan üzüntü, ağrı ve stresin giderilmesinde kullanıldığı bilinmektedir. Osmanlılar gülü bir miktar fermente ederek (ekşiterek) ve su buharı distilasyonunu (imbikten geçirerek) kullanarak yağını elde etmişlerdir. Elde ettikleri bu yağa "sega yağı" adını vermişler. Bu yağı dahilen ve haricen 
birçok hastalığın (bademcik iltihabı, faranjit, boğaz ve solunum yolu hastalıkları) tedavisinde kullanıldığı bilinmektedir. Ayrıca gül kokusunun nörolojik ve psikiyatrik hastalıkların tedavisi edilmesi için aromaterapi yolu ile kullanıldığı bilinmektedir (Özçelik ve ark., 2011).

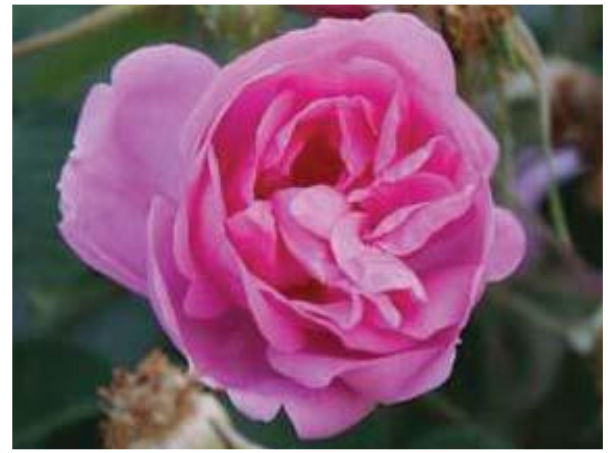

Alzheimer hastalığ ${ }_{1}$ (AD) halk arasında bunama olarak da adlandırılan demansın bir türüdür. Zaman içinde kademe kademe giderek kötüleşir ve aşağıdaki gibi belirtilere neden olabilir: Hafıza kaybı, öğrenme ve dil becerileri (Lambert ve ark., 2009; Seshadri ve ark., 2010). İlerleme ve kesin $A D$ nedenleri halen bilinmemektedir ancak ortaya atılan en yaygın hipotezler, etken faktörler, kolinerjik, amiloid, tau ve metal hipotezleridir (Singh ve ark., 2013). AD için standart tıbbi tedavi aşağıdakileri içerir: Kolinesteraz inhibitörleri (ChEI'ler) ve kısmi N-metil-D-aspartat (NMDA) antagonistleri (Massoud ve Léger, 2011). Kolinerjik hipotez, AD patogenezini özetleyen en eski ve en popüler hipotezdir. Kolinerjik hipoteze göre, $\mathrm{AD}$ için geçerli olan farmakoterapi, kolinesteraz enzimlerinin (ChEs) inhibisyonu yoluyla asetilkolin (ACh) seviyesinin artırılmasıdır (Singh ve ark., 2013). Asetilkolinesteraz (AChE) ve bütirilkolinesteraz (BChE), merkezi sinirde sisteminde (CNS) lokalize olmuşlardır, nörotransmitter olan ACh'i hidroliz edebilirler. Çalışmalar AD'nin AChE'nin hızlı kaybıyla tanımlandığını göstermiştir. Hastalığın erken safhasındaki aktivitenin yanı sıra hastalık ilerledikçe AChE oranı artmaktadır (Darvesh ve ark., 2003; Massoud ve Léger, 2011). BChE'nin rolünden dolay1 asetilkolinin hidrolizi, her iki kolinesterazın inhibitörü, beyinde ACh düzeylerinde artışa neden olarak, Alzheimer hastalığında daha başarılı bir klinik etkinliği sağlar (Basiri ve ark., 2013).

$\mathrm{Bu}$ çalışmanın amacı, gül suyunun $\mathrm{AChE}$ ve $\mathrm{BChE}$ enzimleri için inhibisyon potansiyelinin belirlenmesidir.

\section{Materyal ve Yöntem}

\subsection{Materyal}

$\mathrm{Bu}$ çalışmada kullanılan kimyasal reaktifler ve çözücüler Sigma Aldrich (Münih, Almanya). Gül suyu ise SEBAT Gül yağı ve Uçucu yağlar San. Ve Tic. Ltd. Şti. Keçiborlu-Isparta'dan temin edildi.

\subsection{AChE ve BChE için inhibisyon çalışmaları}

AChE, BChE, 5,5-ditiyobis- (2-nitrobenzoik asit) DTNB, asetiltiokolin iyodid (ATCI) be butiriltiyokilin iyodat (BTCI) Sigma Aldrich'den satın alındı. Gül suyunun AChE ve BChE'ye karşı inhibitör aktiviteleri Ellman'ın kolorimetrik yönteminde bazı değişiklikler yapılarak kullanıldı. Test için kullanılan gül suyu saf su kullanılarak seyreltildi ve daha sonra $50 \mathrm{mM}$ Tris tamponu ( $\mathrm{pH}$ 8.0) ile nihai konsantrasyona ayarland. Küvet içeriği $50 \mathrm{mM}$ Tris tamponu $\mathrm{pH}: 8.0), 3 \mathrm{mM}$ DTNB (Ellman's Reaktif), $0.2 \quad \mathrm{U}^{-1}$ enzim (AChE/BChE) ve bir $15 \mathrm{mM}$ substrat (ATCI/BTCI). Reaksiyonun absorbansı karışım daha sonra her 5 dakika 412 nm'de üç kez ölçülmüştür (Ellman ve ark., 1961). Bileşiklerin $\mathrm{IC}_{50}$ değerleri, yüzde inhibisyona karşı inhibitör konsantrasyonu olarak hesaplandı.

\subsection{In vitro $A C h E$ ve $B C h E$ enzimlerinin gül suyuna karşı inhibitör aktivitleri}

Gül suyunun AChE ve BChE'ye karşı inhibitör aktiviteleri kolorimetrik teste göre ölçüldü (Ellman ve ark., 1961). Neostigmin referans bir AChE inhibitörü bir bileşiktir. Gül suyu ve neostigmin için $\mathrm{IC}_{50}$ değerleri Tablo 1'de özetlenmiştir. Neostigminle kıyaslandığ zaman gül suyunun $\mathrm{AChE}$ ve $\mathrm{BChE}$ enzimleri üzerinde etkili bir inhibisyon gösterdiği tespit edildi. Bu enzimler için elde edilen $\mathrm{IC}_{50}$ grafikleri Şekil 1 ve 2 'de gösterilmiştir. $\mathrm{IC}_{50}$ değerleri AChE için $0,6227 \mu \mathrm{g} \mathrm{ml}^{-1}$ $\mathrm{BChE}$ için $0,1956 \mu \mathrm{g} / \mathrm{ml}$ olarak belirlendi.

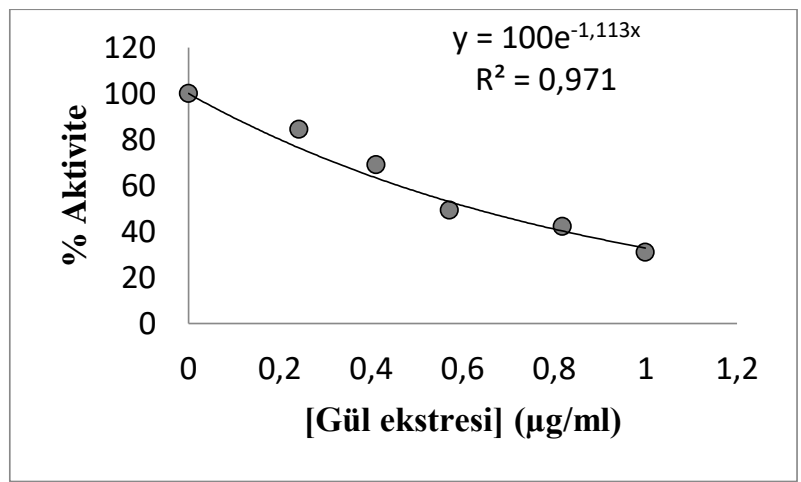

Şekil 1. Gül suyu ile AChE IC $\mathrm{I}_{50}$ grafiği.

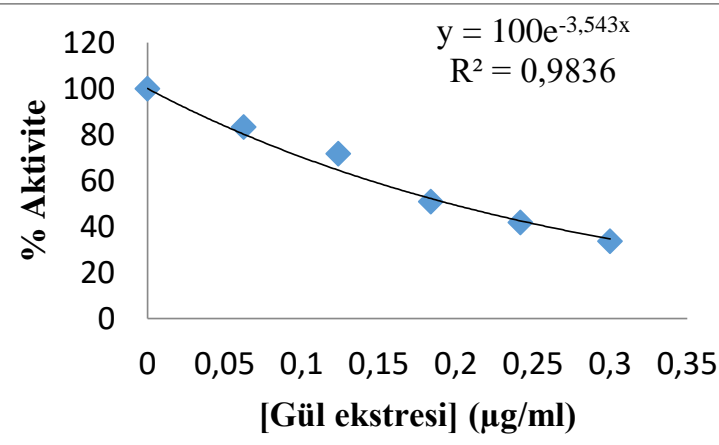

Şekil 2. Gül suyu ile BChE IC $\mathrm{B}_{50}$ grafiği. 


\section{Bulgu ve Tartışma}

Beyinde gözlenen en önemli değişim, bir nörotransmitter olan asetilkolinin korteks seviyelerindeki azalmadir. $\mathrm{Bu}$ nedenle, AChE'nin inhibisyonu beyindeki asetilkolin seviyesini yenileyebilir (Howes ve Houghton, 2003). Alzheimer hastalıklarının tedavisinde kullanılan ilaçların çoğu enzim inhibitörü olarak tasarlanmıştır galantamin gibi (Mukherjee ve ark., 2007). Gül yağının içeriğinde bulunan sitronellol (\% 31-44), geraniol (\% 9-14), nerol (\% 5-11) gibi oksijenli monoterpenler ile nonadekan (\% 8-15), nonadeken (\% 2-5) gibi hidrokarbonlar ana bileşiklerdir (Baser ve ark., 2012).

Gülsuyunun karakteristik bileşiği, feniletil alkoldür. Eski kaynaklarda, gülün kalp ve beyin üzerindeki olumlu etkilerinden bahsedilir. Yapılan farmakolojik ve klinik çalışmalarda, bu etkileri doğrulayacak sonuçlara ulaşılmıştır. Isparta gülü çiçeklerinin sulu alkollü ekstresinin, izole kobay kalbinde kalp atışını ve kontraktilitesini, muhtemelen betaadrenerjik reseptörler üzerindeki uyarıcı etkisiyle hızlandırdığı gözlenmiştir (Baser ve ark., 2012).

Gül çiçeklerinin tomurcuklarında bulunan siyanidin3-O-glikozit adlı flavonoitin, anjiotensin-I-çevirici (ACE) enzim aktivitesini ciddi şekilde bastırdığı ve bu şekilde kalpdamar fonksiyonlarının iyileştirilmesinde önemli rol oynadığı gösterilmiştir. Zira, ACE, güçlü bir damar daraltıcı (vazokonstriktör) olan anjiotensin II üretimini sağlayan anahtar enzimdir. Gül çiçeklerinin kloroformlu ekstresinin, alzheimer hastalığına neden olan amiloid beta $(A \beta)$ adlı peptitin oluşumunu inhibe ettiği gösterilmiştir. Kloroformlu ekstredeki etkin bileşiğin, kısa adı VLFA olan çok uzun zincirli, 37 karbonlu, çoklu doymamış yağ asidi olduğu anlaşılmıştır. Gülyağı ve gül kokusunun karakteristik bileşiği olan feniletil alkolün, asetilkolin esteraz (AChE) ve butirilkolin esteraz (BChE) enzimlerini inhibe ettiği; yani hafıza kaybının önlenmesinde, yardımcı olabileceği belirlenmiştir (Senol ve ark., 2013).

Esfandiary ve ark. Rosa damascena'nın amyloid$\beta$ 'nın neden olduğu davranışsal açıkları tersine çevirebileceği ve Alzheimer hastalığında bilişsel işlev bozukluğunun önlenmesi ve tedavisi için yeni bir potansiyel seçenek sunabileceği sonucuna varmışlardır (Esfandiary ve ark., 2015). Homayoun ve ark. Rosa damascena'nın hidro-alkolik ekstraktının antikonvülsan ve nöro-koruyucu etkilere sahip olduğunu göstermiştir (Homayoun ve ark., 2015). Rosa damascena, geleneksel tıpta önemli bir yere sahiptir. Modern tıbbın terapötik uygulamaları ile ekonomik olarak değerli bir bitkidir. $R$. damascena'nın antimikrobiyal, antioksidan, analjezik, antiinflamatuvar, anti-diyabetik ve anti-depresan özellikleri doğrulanmıştır (Mahboubi, 2015).

AChE ve BChE'ye karşı test edilen gül suyunun önleyici potansiyeli Ellman metoduna göre denenmiştir (Ellman ve ark., 1961). Grafikleri kullanarak hesaplanan bileşiklerin $\mathrm{IC}_{50}$ değerleri Şekil 1 ve 2'de verilen grafikler yardımı ile hesaplanmış ve Tablo 1'de gösterilmiştir.

Tablo 1. Gül suyu ve klinik olarak kullanılan inhibitör (Neostigmin) için $\mathrm{AChE}$ ve BChE inhibisyon verileri

\begin{tabular}{lcc}
\hline İnhibitör & $\begin{array}{c}\mathrm{AChE} \mathrm{IC}_{50} \\
\left(\mu \mathrm{g} \mathrm{ml}^{-1}\right)^{\mathrm{a}}\end{array}$ & $\begin{array}{c}\mathrm{BChE} \mathrm{IC}_{50} \\
\left(\mu \mathrm{g} \mathrm{ml}^{-1}\right)^{\mathrm{a}}\end{array}$ \\
\hline Gül suyu & $0,6227 \pm 0,012$ & $0,1956 \pm 0,007$ \\
Neostigmin & $0,4398 \pm 0,010$ & $0,3403 \pm 0,010$ \\
\hline${ }^{a}$ AChE ve BChE'nin \%50 inhibitör konsantrasyonu (üç deneyin \pm SD \\
ortalaması)
\end{tabular}

\section{Sonuç}

Sonuç olarak, bu çalışmada gül suyunun $\mathrm{AChE}$ ve $\mathrm{BChE}$ enzimlerinin etkilediği belirlenmiştir. Bulgularımız, örneğin olası geri dönüşümlü AChE ve BChE inhibitörlerin bir başka sınıfını göstermektedir galantamin, rivastigmin, takkim vs. Aslında, araştırılan bu bileşikler burada düşük mikromolar aralıkta etkin AChE inhibitör aktivitesi bu türevlerin cesaret verici AChEI ajanlar olabileceğini göstermektedir.

$\mathrm{Bu}$ maddeler Alzheimer hastalığının tedavisinde faydalı olabilecek yeni AChE ve BChE inhibitörlerini belirlemek için kullanılabilir.

\section{Kaynaklar}

Baydar, H., 2005. Tibbi, Aromatik ve Keyf Bitkileri (Bilim ve Teknolojisi), Süleyman Demirel Üniversitesi Yayınları, No: 51 .

Baser, K.H.C. Altintas, A., Kurkcuoglu, M., 2012. "Turkish Rose: A review of the history, ethnobotany and modern uses of rose petals, rose oil, rose water and other rose products", HerbalGram 96: 40-53.

Basiri, A., Murugaiyaha, V., Osman, H., et al. 2013. An expedient, ionic liquid mediated multi-component synthesis of novel piperidone grafted cholinesterase enzymes inhibitors and their molecular modeling study. Eur. J. Med. Chem., 67: 221-229.

Darvesh, S., Hopkins, D.A., Geula, C., 2003. Neurobiology of butyrylcholinesterase. Nat. Rev. Neurosci. 4, 131-138.

Ellman, G.L., Courtney, D., Andies, V., Featherstone, R.M., 1961. A new and rapid colorimetric determination of acetylcholinesterase activity. Biochem. Pharmacol., 7: 88-95.

Esfandiary, E., Karimipour, M., Mardani, M., Ghanadian, M., Alaei, H.A., Mohammadnejad, D., Esmaeili, A., 2015. Neuroprotective effects of Rosa damascena extract on learning and memory in a rat model of amyloid- $\beta$ induced Alzheimer`s disease Neuroprotective effects of Rosa damascena extract on learning and memory in a rat model of amyloid- $\beta$-induced Alzheimer`s disease. Adv. Biomed. Res. 4: 131-140.

Homayoun, V., Seghatoleslam, M., Pourzaki, M., Shafieian, R., Hosseini, M., Ebrahimzadeh, B.A., 2015. Anticonvulsant and neuroprotective effects of Rosa damascena hydro-alcoholic extract on rat hippocampus. Avicenna. J. Phytomed, 5 (3): 260-270. 
Howes, M.J., Houghton, P.J., 2003. Plants used in Chinese and Indian traditional medicine for improvement of memory and cognitive function. Pharmacol. Biochem. Behav., 75(3):513-27.

Lambert, J., Heath, S., Even, G., et al. 2009. Genome-wide association study identifies variants at CLU and CR1 associated with Alzheimer's disease. Nat. Genet., 41: 1094-1099.

Mahboubi, M., 2015. Rosa damascena as holy ancient herb with novel applications. J. Tradit. Complement. Med. 6(1), 10-16.

Massoud, F., Le'ger, G., 2011. Pharmacological treatment of Alzheimer disease. Can. J. Psychiatry. 56, 579-588.

Mukherjee, P.K. Kumar, V. Mal, M., Houghton, P.J., 2007. Acetylcholinesterase inhibitors from plants. Phytomedicine, 14 (4): 289-300.

Özçelik, H., Muca, B., Özavcı, A.G.M., 2011. Isparta Yağ gülü (Rosa $\mathrm{x}$ damascena Mill.) Yağı ve Çiçeklerinin
Strese Bağlı Nörolojik ve Psikiyatrik Hastalıklara Etkileri. Biyoloji Bilimleri Araştırma Dergisi, 4(2): 99105 .

Özçelik, H., Yildirim, B., Muca, B., 2013. Rosa damascena Mill.' nın Türkiye' de Varyasyonu. Suleyman Demirel University Journal of Natural and Applied Science, 17(2): 52-60.

Senol, F.S., Orhan, I.E., Kurkcuoglu, M., Khan, M.T.H., Altintas, A., Sener, B., Baser, K.H.C., 2013. A mechanistic investigation on anticholinesterase and antioxidant effects of rose (Rosa damascena Mill.). Food Research International, 53; 502-509.

Seshadri, S., Fitzpatrick, A.L., Ikram, M.A., et al. 2010. Genome-wide analysis of genetic loci associated with Alzheimer disease. J. Am. Med. Assoc., 303, 1832-1840.

Singh, M., Kaur, M., Kukreja, H., Chugh, R., Silakari, O., Singh, D., 2013. Acetylcholinesterase inhibitors as Alzheimer therapy: from nerve toxins to neuroprotection. Eur. J. Med. Chem., 70, 165-188. 